\title{
How green facades affect the perception of urban ambiences: Comparing Slovenia and the Netherlands
}

Green facades are gaining growing attention among the general public and researchers in various disciplines. Vertical greenery systems play an important role as expressive elements of buildings, while at the same time being treated as a special type of green infrastructure with various positive effects, especially in densely built-up urban areas. This study focuses on the perception of green facades in urban ambiences. The emphasis is on visual perception and the evaluation of the pleasantness or visual quality of various spaces based on the presence or absence of green facades. The public perceptions and evaluation of urban open space with the green elements studied was examined in the Netherlands and Slovenia. The online survey included images of various spatial situations about which respondents conveyed their opinions. Two target groups were addressed: the general public and architecture and urban planning students. The results show that in general greener urban environment is perceived as more pleasant, suggesting that most people think vertical greenery also contributes to the quality of urban ambiences. Nonetheless, differences were identified between the residents of the two countries studied and the two groups surveyed.

Keywords: vertical greenery, green facades, living walls, perception of urban space, green infrastructure 


\section{Introduction}

Because of the environmental problems identified and changes that also affect the urban quality of life, awareness of the importance of natural elements in cities is increasing among both the professional community and the general public. These increasingly highlighted topics are also included in modern urban planning strategies, which not only focus on using sustainable construction materials, but also reflect on envisaged natural processes that can help improve the built environment. This may entail anything from providing a larger share of green areas and planting trees to using greenery on buildings, in which using plants in designing building envelopes is especially highlighted in densely built parts of cities (Medl et al., 2017). Vertical greenery and green roof systems are elements of green infrastructure, representing a part of a city's or town's green system (Šuklje Erjavec et al., 2020), whose functions they perform (i.e., ecological, environmental, climate, design, cultural, economic, and social functions). Even though greening buildings was already practiced in the past, green roofs and walls are now becoming a synonym for an innovative form of urban greening, especially in large cities with warm, humid climates (Wong et al., 2010a). In Asian cities in particular, ideas of biophilic urbanism and designing vertical and forest cities are emerging (Guan et al., 2018). The media present various examples of integrating vegetation into architecture, promoting their use across the globe (Černigoj, 2018). Because the application of biotechnological building envelope systems depends on climate, research results are not necessarily transferrable and comparable across countries. For example, a Greek opinion survey (Tsantopoulos et al., 2018) explored the occurrence or perceptions of green infrastructure in cities. Its results showed that the aesthetic aspect of greening buildings in Athens is significantly more important and present in the people's minds than its impact on improving the microclimate and environmental parameters. On the other hand, a Malaysian study (Mansor et al., 2017) reveals that the residents view vertical greenery as a form of street art that has a certain effect on the environment, which is why they also value it highly. Taking into account the findings of studies from warmer climates, the authors of this article were interested in the public perception of and general attitude toward green facades in Europe's temperate climate zone. In particular, this study examines the perceptions of spatial users in the Netherlands and Slovenia.

\subsection{Green facades as an integral part of infrastructure}

Vertical greenery is used on various types of buildings, in various spatial contexts, and in various forms. The method of integrating green elements into the building envelope is usually connected with the architectural and design concept of an individual building. The entire envelope and especially the facade plays an expressive role. In central Europe, green roofs are generally more common than green facades. Examples of modern architecture designs with a building envelope completely covered in greenery, such as the one in the Netherlands (Internet 4), are rare. The application of a suitable vegetation system is closely connected with specific climate and micro-location conditions that dictate the selection of materials. In the first stage of planning, the concept, type, and maintenance of vertical greenery must be defined to achieve the desired design goals. The results of a Singapore study of green facades showed that a lack of technical information, maintenance instructions, and information on vegetation may become a barrier to installing these systems (Wong et al., 2010b), which are generally considered a potential in future architecture and construction. They are also treated similarly by Italian researchers. Perini and Rosasco (2013) analysed the costs and benefits of green building envelopes. They explored their impact on the building and the surrounding area, especially in terms of environmental, economic, and social improvements, drawing attention to the difficulty defining the effects of these systems on the outdoor space.

The definition of green facades used in this study was developed based on an overview of terminology used in several studies (Jim, 2015; Pfoser, 2016; Bustami et al., 2018). Accordingly, green facades or walls are defined as vertical vegetation systems integrated into the buildings' outer walls (or envelope), either directly or through a support. There are diverse typologies of vertical greenery determined by the construction elements, the method of installing vegetation, and the vegetation selected. Despite various approaches to classifying these elements, two basic types are defined based on physical characteristics: green facades and living walls. Green facades are ground-bound systems with climbing plants growing up or along the wall and green walls are systems with plants growing from an element attached to the wall without coming in contact with the ground (Bustami et al., 2018). Because these vertical systems are always bound to the building's wall, they help shape the dialogue between the built and natural environments.

\subsection{Urban space perceptions}

Urban environments and the way people experience urban spaces are explored by a variety of studies. In studying green facades, the socio-psychological aspect is interconnected with other aspects that affect perception and public opinion (Köhler, 2008). Perception is a process that involves all human senses and is composed of several stages. Bell (2001) 
defines the following three: sensing (in which a connection with stimuli is established), processing and organizing information (where the recipients' past experiences are important), and cognition (which includes interpretation and evaluation connected with the culture and social status of the recipient or subject). The perception of architecture, the built environment, and open space is intermodal, which means it involves a combination of various senses. The majority of information (c. 70\%) is obtained through sight (Fieandt, 1966). According to various authors, space and architecture need to be personally experienced (Rasmussen, 2001), because people's perception of space is multi-layered - that is, connected with physical and functional spatial characteristics on the one hand and meanings on the other. Drawing from Relph (1976), a complex explanation was developed by Punter (1991) and Montgomery (1998) (cited in Carmona et al., 2003). They identified three aspects of "place" for use in urban design. They believe that a place is the result of the relationship between the physical characteristics of space, the activities that take place in it, and the symbolic meanings attributed to it by its users. The combination of these aspects has an important impact on the perception of the hierarchical position of a particular open space within the urban structure.

The culturological dependence of spatial perception has been proven in various studies. Passini (1992) highlights the connection between patterns of environmental perception and people's need or capability to adapt to the environment; if a cultural milieu is (forced to be) in touch with nature or natural processes, its perception of space is more complex. European researchers report that in European culture the perception of space is primarily tied to the physical structure of space (Jackson, 1994; Nikšič, 2008), which they explain with the multi-layered physical structure of European cities, which have developed over the centuries through various and distinct morphological forms. In turn, US studies show that residents do not associate a specific place so much with its architectural character or spatial design, but more with the developments and events taking place in it. Along similar lines, Rapoport (1977) distinguishes between "Western" culture and indigenous cultures, arguing that Western culture primarily perceives space based on its physical and functional characteristics, whereas indigenous cultures, such as Australian Aborigines, perceive space through its mythological meanings and symbols. In Slovenian urban design, pure perception studies are rare. Nikšic (2008) establishes that the perception of urban public open space is largely affected by its physical characteristics, followed by its functional characteristics, whereas symbolic meanings play only a small role.

\subsection{Green elements in urban ambiences}

The perception of green elements within urban design is diffcult to examine outside the spatial context. This study explores people's attitudes toward urban ambiences in terms of the presence of green facades. It is assumed that green facades affect perception of the space in which they are located. As green element with their physical characteristics, green facades affect the relationship between solids and voids, scales, proportions, surfaces, texture, rhythm, uniformity of material (or a lack thereof), and so on. In addition, the semantic relationships between natural and built environments, various interpretations of the sustainability paradigm, and the general attitude toward natural elements in the urban environment are also important.

Studies explore the perception of the urban environment and its natural elements in various ways. Studies dealing with the integration of the natural environment and design focus on people and their need to perceive natural processes in time and space (Hayles \& Aranda-Mena, 2018), and the connection between the effects of the presence of natural elements, especially vegetation, on the everyday experience of the environment and the extent of using that environment. Green streets have been proven to have a major impact on urban walkability and hence also the residents' physical activity (Lu et al., 2018). A major positive effect of vegetation on perception has also been established in a study of urban noise (Van Renterghem, 2019). The visual presence of vegetation mitigates the perception of annoying environmental noise, which is why green spaces are perceived as more pleasant than those without vegetation. In relation to green building envelopes, White and Gatersleben (2011) explored whether green buildings (with green roofs and walls) are more valued than those without integrated vegetation, establishing a preference for green buildings. Public perception and opinion studies often apply questionnaires with examples of the presence or absence of a specific stimulus. A similar use of stimuli (both negative and positive) is also common in other disciplines, such as in examining the physiological sensory processes themselves or measuring responses or activity in the brain hemispheres (O'Hare et al., 2017).

The hypothetical premise of this study is that people perceive urban spaces that include vegetation as more pleasant (likeable). The aim is to verify this hypothesis by analysing green walls as elements of urban green infrastructure. The key questions arising in this regard are as follows:

- Does the presence of green facades affect the perception of ambience pleasantness?

- Does the amount of vegetation affect the evaluation of ambience pleasantness?

- Do people show preferences for certain types of green facades? 
The central part of this study examines people's responses and differences in their answers. In addition to the public opinion, the views of selected groups are also examined. The study raises not only the issue about the perception of vertical greenery, but also people's preferences for specific types of open space and the physical characteristics that affect its degree of attractiveness.

\section{Research methods}

\subsection{Designing a questionnaire}

The surveying method was selected to collect the public views. In designing the questionnaire and preparing the material for the survey, the following principles were applied: maximum measurability of responses (acquiring independent assessments), adequate representativeness of the material presented, clear questions, and user friendliness (the length of the survey). A publicly accessible online questionnaire in Slovenian and English was designed. The accompanying text at the beginning of the questionnaire informed respondents that the survey was anonymous, what the aim of collecting data was, what the survey dealt with, and how long it was; in addition, recommendations were given to view the images on a computer or use the zoom function with smaller devices (e.g., a smart phone). The questionnaire included questions referring to the images of urban scenes (visual stimuli) and questions investigating the respondents' sociodemographic characteristics. In addition to general questions (about sex, age, education, country of residence, and occupation), additional questions were provided to establish any possible effects on the respondents' preferences (e.g., questions about their living environment).

The respondents were asked to rate every digital image in terms of the attractiveness of a specific urban ambience on a scale of -10 ("not at all") to +10 ("extremely"), using a slider. The images showed twenty spatial situations (diverse urban spaces) in three different versions. All sixty images (stimuli) were shown in a mixed order determined in advance. The random order, in which different urban spaces and greening versions followed one another, was used to minimize any mutual influence between the individual stimuli. Although possible start and end effects in applying picture surveys were considered (Strumse, 1994), no additional images were added (which would later be excluded from analysis) because of the large total number of images used (additional images would have made the survey longer).

\subsection{Visual stimuli}

Images of spatial situations were prepared in a way that also makes it possible to process them with other methods and compare results in the future. The images were edited in a uniform way and included in the questionnaire such that the respondents could focus on an individual stimulus. The images did not include changes to the built environment and architecture; the simulations only showed changes to the elements studied - that is, green facades. From the perspective of studying urban space, different urban ambiences and options for incorporating vertical greenery in them were selected. Each open space was presented in three versions: A) without greenery on the walls, B) with a medium amount of greenery on the walls, and C) with dense or a high amount of greenery on the walls. In terms of the type of vertical greenery, images featured either green facades (twenty-two images) or living walls (eighteen images).

The images used to present various urban spaces included photos of real situations and edited photos of these situations in two variations. 3D renders or visualizations were used to a smaller extent. Because the study focused on the users of urban space, images taken from the pedestrian's point of view or the user's scale were used. Images with visible spatial context were selected on purpose because this context is key to understanding the ambience itself, the element studied, and the spatial relationships (e.g., close-ups and long shots), allowing respondents to rate a specific ambience (i.e., offer their views on the presence of a green wall in this environment). Images were selected from which the viewer can infer the type of the outdoor space (e.g., a street, parking area, playground, etc.) and the type of the building (e.g., residential, industrial, commercial, or public building). The selected examples included in the survey comprised: public open spaces (six), areas next to public buildings (seven), residential areas (five), and shopping areas (two examples). In terms of the physical characteristics and use of the spaces presented, these examples were further divided into the following types:

- Open spaces that function as streets (primarily ambiences that people can walk through) and other multi-purpose areas where people perform various activities and spend time (e.g., squares and playgrounds);

- Spaces next to various types of public buildings (an image of a public building, taking into account a potential different interpretation; spaces next to schools, and visualizations of planned construction included as a separate group of images);

- Residential areas (real situations and visualizations of apartment buildings);

- Shopping centres (typical large-scale buildings).

The images used included the author's field photos, 3D visualizations (images) produced by others, and two images available online (Vogelnik, 2013; Internet 1; Internet 2; Internet 3; Haesevoets, 2015). To prepare photographic simulations, the 


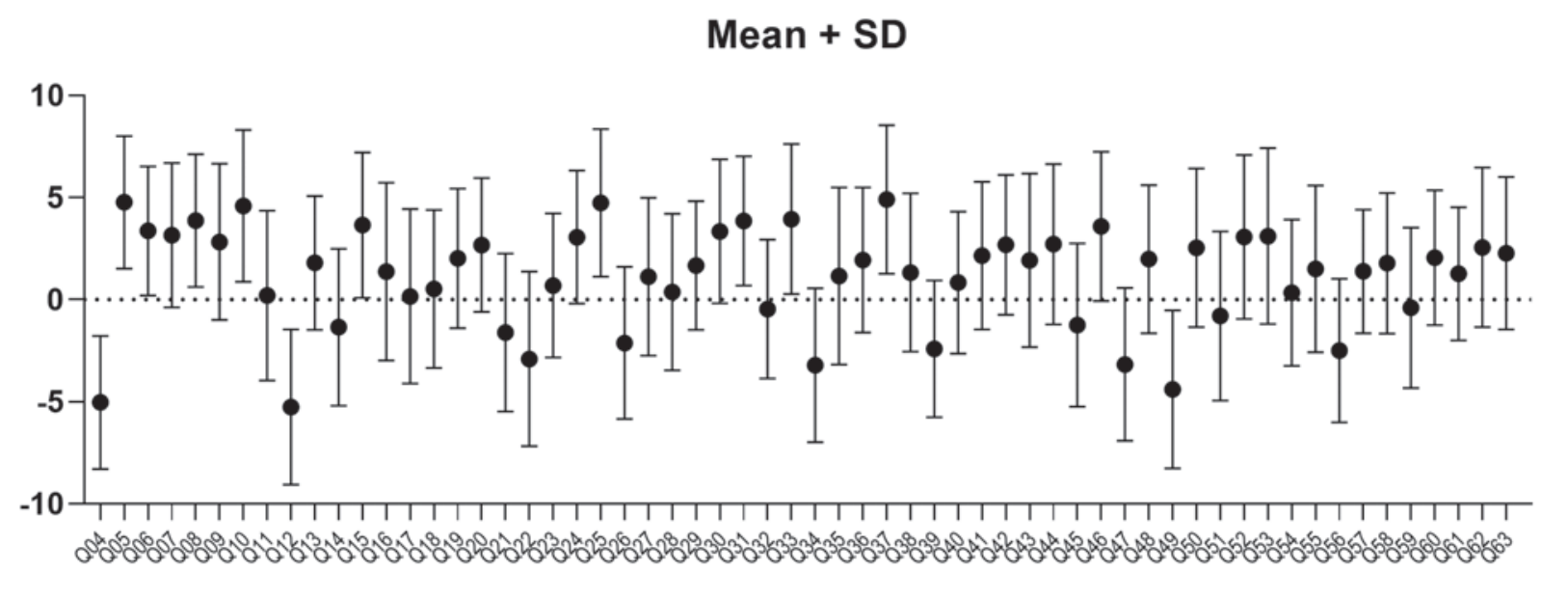

Figure 1: Means and SD for all sixty images ( $n=223$ ) (author: Jana Kozamernik).

\subsection{Data analysis}

digital images were manipulated using the digital image editing program Adobe Photoshop CS3. Image editing focused on changing the facades in the original image. To exclude the impact of other factors on rating individual images, no changes were made to other (outdoor) spatial elements or architectural design, and the number of people shown was approximately the same in all images.

\subsection{Collecting data}

This study used the online survey tool $1 \mathrm{KA}$ developed by the University of Ljubljana Social Informatics Centre. The survey was conducted in the Netherlands and Slovenia during the summer of 2019 (from June to September). To obtain as large a representative sample as possible an e-mail invitation was sent to various recipients in both countries. In addition, personal invitations were sent by post to a smaller portion of addressees, primarily the elderly. The survey focused on obtaining data for two groups: the general public and younger representatives of the professional community. The random sample of the general public included individuals that are not professionally involved with architecture or urban planning. The sampling for the second group was carried out among architecture and urban planning students (and, to a smaller extent, landscape architecture students). To ensure the professionals group was sufficiently representative, it included students of various years and study tracks. The aim was to obtain data for all age groups, the most diverse population structure as possible, and diverse occupational profiles.
Statistical calculations were made with SPSS for Windows, in combination with Microsoft Excel and GraphPad Prism 8.3.0. The valid data obtained from both surveys (originally sampled in Slovenia and the Netherlands) were combined into a single database, from which all invalid questionnaires (i.e., incomplete questionnaires, questionnaires with missing answers, and questionnaires in which respondents did not rate all the images) and errors were subsequently eliminated. A total of 233 valid questionnaires were obtained: 131 from Slovenia and ninety-two from the Netherlands. The basic calculations for the first, visual section of the survey (with images and slider ratings) included the means and standard deviations (dispersion of values), and a detailed analysis of the visual images was conducted by comparing the frequencies of ratings provided for an individual image. The analysis was conducted by examining the following design indicators:

- Ratio between the built and green environments; the three versions of the same ambience were labelled A (without greenery on the walls), B (with a medium amount of greenery on the walls), and C (with a high amount of greenery on the walls);

- Type of vertical greenery system: green facades (GF) or living walls (LW);

- Type of urban space: public open space with a multipurpose function, such as squares and playgrounds (Oo), streets or open space next to streets (Os), spaces next to public buildings ( $\mathrm{Pi}$ ), areas next to schools (Ps), 3D renders of areas next to public buildings (Pr), residential areas $(R)$, residential areas with a potentially different interpretation $(\mathrm{Ri}), 3 \mathrm{D}$ renders of residential areas $(\mathrm{Rr})$, and shopping areas $(S)$. 




Q12

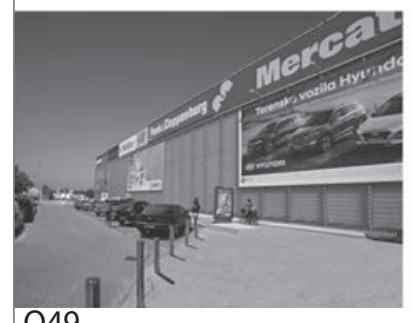

Q49

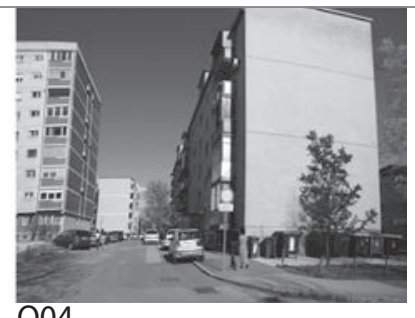

Q04



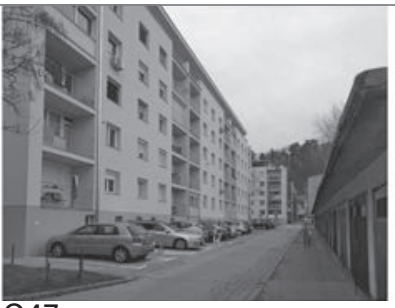

Q47



Q56



Q22



Q39

Table 1: Ten (out of sixty) lowest rated images based on their mean values $(n=223)$.

\begin{tabular}{lllllllllll}
\hline Image* & Q12 & Q4 & Q49 & Q34 & Q47 & Q22 & Q56 & Q39 & Q26 & Q21 \\
\hline Mean & -5.26 & -5.03 & -4.40 & -3.22 & -3.17 & -2.90 & -2.49 & -2.41 & -2.12 & -1.61 \\
\hline $\mathrm{P}(1-20)^{* *}$ & 1 & 11 & 17 & 15 & 8 & 2 & 10 & 9 & 7 & 17 \\
\hline A/B/C & $\mathrm{A}$ & $\mathrm{A}$ & $\mathrm{A}$ & $\mathrm{A}$ & $\mathrm{A}$ & $\mathrm{A}$ & $\mathrm{A}$ & $\mathrm{A}$ & $\mathrm{A}$ & $\mathrm{B}$ \\
\hline Space & $\mathrm{S}$ & $\mathrm{R}$ & $\mathrm{S}$ & $\mathrm{Ps}$ & $\mathrm{R}$ & $\mathrm{Os}$ & $\mathrm{Ps}$ & $\mathrm{Ps}$ & Os & $\mathrm{S}$ \\
\hline Wall & $/$ & / & $/$ & $/$ & $/$ & $/$ & $/$ & $/$ & $/$ & LW \\
\hline
\end{tabular}

Note: *sequential number of the image in the questionnaire; ${ }^{* *}$ selected example (photo or 3D render)

Figure 2: Images with the lowest mean ratings ( $n=223)$ (author: Jana Kozamernik).

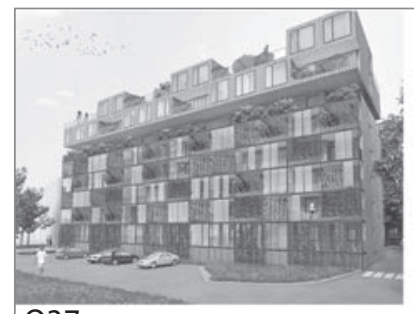

Q37

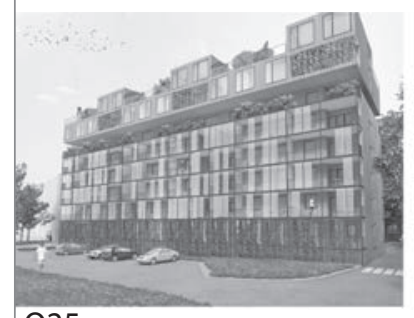

Q25



Q05

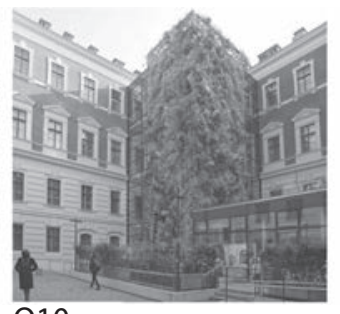

Q10

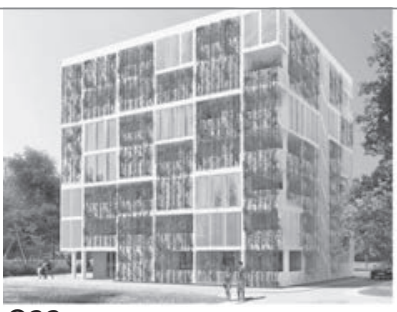

Q33



Q31



Q08

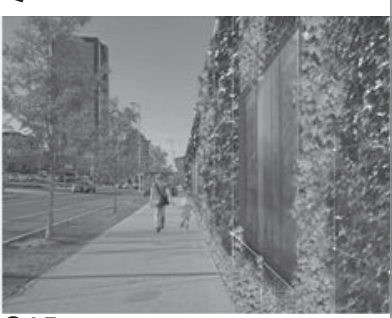

Q15

Table 2: Ten (out of sixty) best rated images based on their mean values $(n=223)$.

\begin{tabular}{lllllllllll}
\hline Image & Q37 & Q5 & Q25 & Q10 & Q33 & Q8 & Q31 & Q15 & Q46 & Q6 \\
\hline Mean & 4.91 & 4.77 & 4.74 & 4.59 & 3.95 & 3.87 & 3.86 & 3.65 & 3.59 & 3.37 \\
\hline $\mathrm{P}(1-20)$ & 5 & 18 & 5 & 14 & 6 & 18 & 10 & 2 & 4 & 10 \\
\hline A/B/C & C & C & B & C & B & B & C & C & B & B \\
\hline Space & $\mathrm{Rr}$ & Oo & $\mathrm{Rr}$ & $\mathrm{Pi}$ & $\mathrm{Rr}$ & Oo & $\mathrm{Ps}$ & $\mathrm{Os}$ & $\mathrm{Ri}$ & $\mathrm{Ps}$ \\
\hline Wall & $\mathrm{GF}$ & $\mathrm{GF}$ & $\mathrm{GF}$ & $\mathrm{GF}$ & $\mathrm{GF}$ & $\mathrm{LW}$ & $\mathrm{GF}$ & $\mathrm{GF}$ & LW & GF \\
\hline
\end{tabular}

Figure 3: Images with the highest mean ratings ( $n=223)$ (author: Jana Kozamernik). 


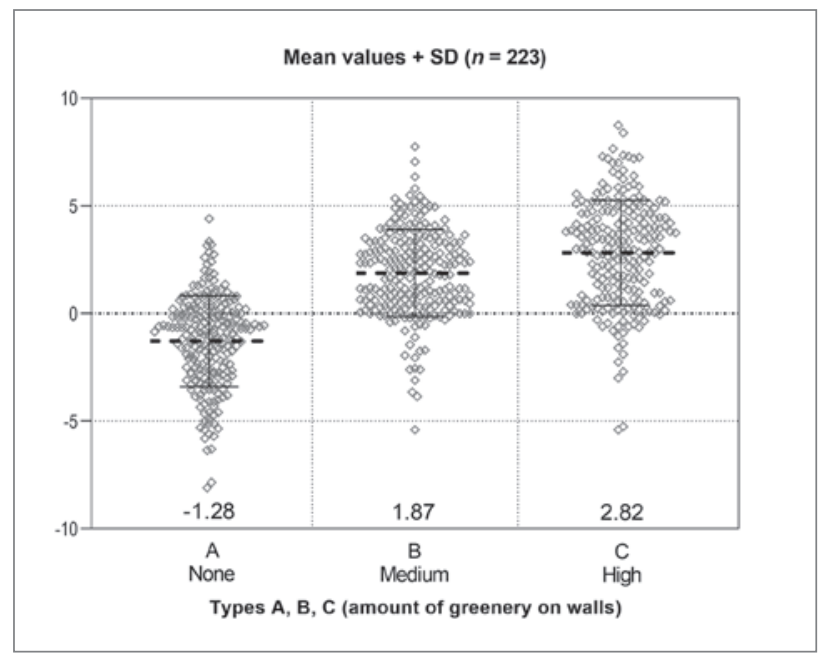

Figure 4: Mean values and $S D$ of images grouped in categories A (without greenery), B (a medium amount of greenery), and C (a high amount of greenery) in the total sample $(n=223)$ (author: Jana Kozamernik).

\section{Results}

\subsection{Demographic characteristics}

The respondents comprised $58.7 \%$ women and $41.3 \%$ men. In both countries the survey included people of various ages, mainly the active working population and young individuals. Most respondents belonged to the under twenty-five age group (50.6\%), followed by those between twenty-six and thirty-five $(19.3 \%$,) thirty-six and fifty $(15.7 \%)$, fifty-one and sixty-five (10.8\%), and over sixty-five (3.6\%). In terms of education, $24.2 \%$ of respondents had a bachelor's degree (EQF level 6), 28.3\% had a master's degree (EQF level 7), and 32.2\% had an EQF level 5 qualification. The shares of respondents with an EQF level 4 qualification and an EQF level 3 qualification or lower were smaller (i.e., $5.4 \%$, respectively), as was the share of those with the highest, EQF level 8 qualification or doctoral degree (4.5\%). In terms of the living environment, most respondents came from urban environments (28.3\%), followed by those from small rural settlements $(23.3 \%)$, downtown areas $(21.5 \%)$, the suburbs $(20.6 \%)$, and the countryside (6.3\%).

\subsection{Preferences regarding the images presented}

The frequency distributions of respondent ratings of individual images in the survey showed a trend of concentration and skewing in a negative or positive direction. Based on the means calculated, a rating for every image was obtained (Figure 1) along with the standard deviations of the mean values, which show a fairly high dispersion of responses $(S D=3.1-4.3)$.

By ranking the visual stimuli from the ones rated the most positive (most attractive) to those rated the most negative (un- attractive), it can be established that the ten least attractive images (Table 1) include all group A images (the version without green facades), except one. They feature outdoor areas of shopping centres (the two images rated the lowest), residential areas (two images), public buildings (three images), and street ambiences. The image of an outdoor area of a shopping centre with a partial green facade (living wall type) was also rated the lowest $(-10)$. Images that were rated the lowest are shown in Figure 2.

An overview of images with the highest average ratings shows that respondents evaluated green opens spaces as more attractive: the ten best rated images include five group $\mathrm{C}$ images (high amount of greenery on the walls) and five group B images (a medium amount of greenery on the walls). In terms of the type of open space presented, these were images of residential areas, spaces next to public buildings, and other public open spaces (playgrounds and squares; Table 2). The highest rated images are shown in Figure 3. The images that were considered more attractive also included three 3D renders of apartment buildings with green facades.

\subsection{Amount of greenery on the walls}

The images were grouped into three categories in order to examine the evaluations of individual urban spaces in terms of the presence or absence of greenery on the walls, or the amount thereof. Figure 4 shows the mean values of all images grouped in category A, B, or C for the entire sample. The results demonstrate that on average the images of urban spaces without vertical greenery (group A) were rated 3.15 points lower than those featuring vertical greenery (groups $B$ and $C$ ). On average, groups $B$ (a medium amount of greenery on the walls) and $\mathrm{C}$ (a high amount of greenery on the walls) were rated as more attractive. In addition, the mean values of these two groups differed by 0.95 points in favour of group C.

By analysing all three versions of an individual urban space image it can be established that in all twenty spaces presented, the group $\mathrm{A}$ images were rated the lowest and group $\mathrm{C}$ images the highest, with a minimal difference between the ratings of group B and C images in some cases. Figure 5 shows one of the twenty open spaces included in the survey. The frequency distributions of individual images' ratings show differences between the Slovenian and Dutch samples, but nonetheless a similar trend of ratings can be observed in both countries.

\subsection{Comparison by demographic characteristics and samples}

A comparison between the Slovenian and Dutch samples shows that in general Slovenian respondents rated the images 


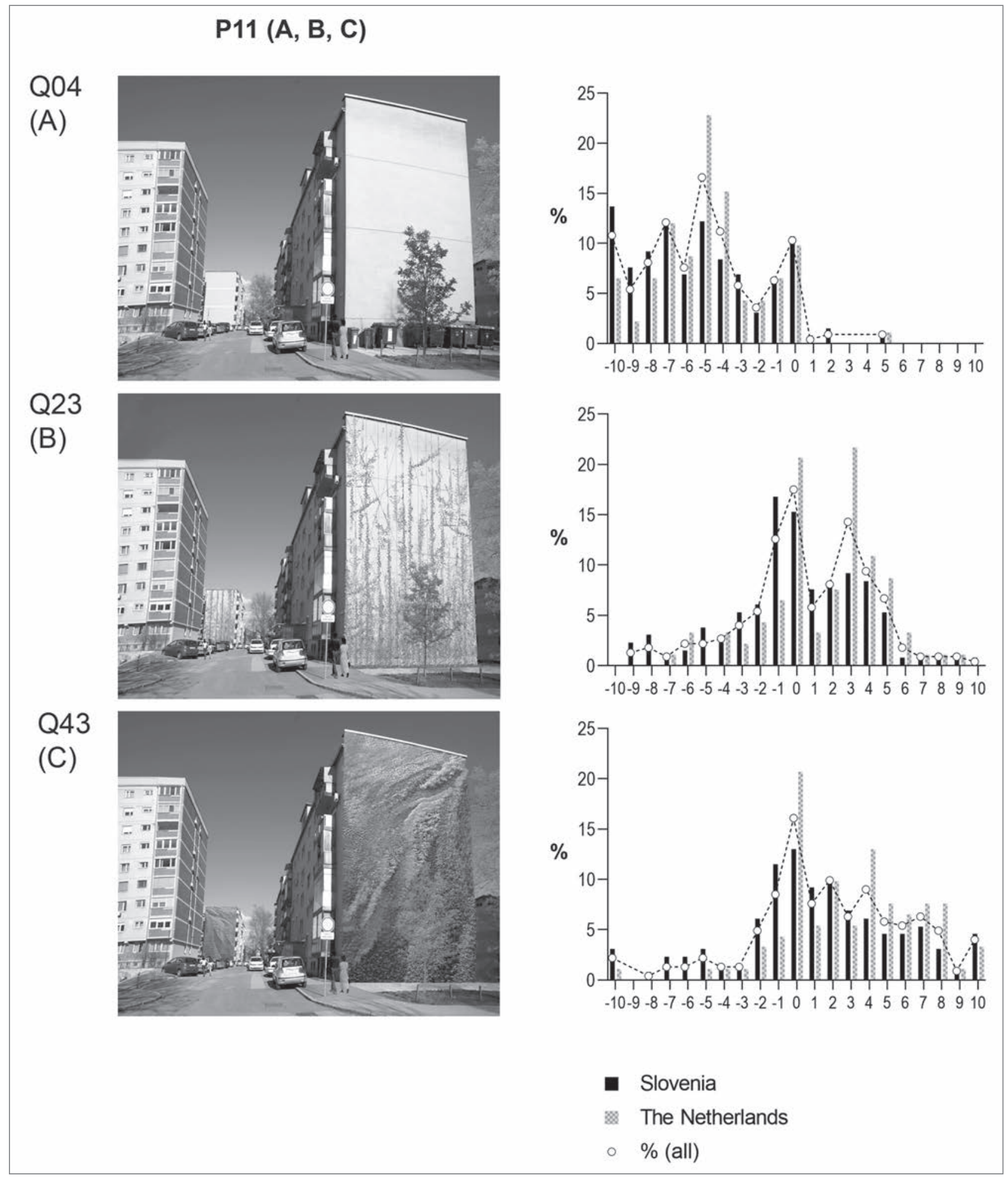

Figure 5: Three versions (A, B, and C) of one of the twenty cases presented and the frequency distributions for both countries (author: Jana Kozamernik).

lower than their Dutch counterparts. For seventeen images (out of sixty), the difference in the mean value of the ratings was greater than 1 point, and for two images the difference was even greater than 2 points. Similarly, Slovenian ratings of images in all three categories (A, B, and C) were also lower than those of the Dutch; specifically, they were lower by 0.64 points for category A, 0.63 points for category B, and 0.69 points for category C. Comparing the differences between individual images, the greatest deviations occurred when wellknown themes were displayed (e.g., a well-known building in the Netherlands, which the Dutch respondents rated higher in all three versions of the image). Group A images (without 




Figure 6: Mean values of an image $(A, B$, or $C)$ for both countries (author: Jana Kozamernik).

vertical greenery) were rated the lowest by Slovenian men and Dutch women. Slovenian and Dutch women rated group B and $C$ images (with vertical greenery on the walls) higher than men, and the differences between the two sexes were greater in the Dutch sample. A comparison of the results between the Slovenian and Dutch samples in terms of the respondents' age group shows greater differences. The mean value of ratings provided by the Dutch respondents twenty-six to thirty-five years old is around 0 . From it can be concluded that this age group finds built ambiences without vertical greenery (green facades) neither attractive nor unattractive or, in other words, they find them acceptable. In contrast, the ratings of the Slovenian respondents of the same age are the lowest among all the age groups studied; from this it can be concluded that to them these ambiences are the least attractive. Images featuring green facades were rated the highest by Slovenian respondents in the middle and at the end of their active working life (fifty-one to sixty-five years old) and Dutch respondents thirty-six to fifty years old, representing the active working population. These groups may be better aware of the importance of the contact with nature in one's living environment.

Differences in the evaluation of open spaces were also observed in terms of the respondents' place of residence. On average, the Slovenian respondents living in downtown areas rated group A images lower than the Dutch and the difference was even more pronounced in the ratings of group $\mathrm{B}$ and $\mathrm{C}$ images. Compared to the respondents living in other environments, the residents of Slovenian downtown areas rated all three categories of images the lowest (their ratings were the lowest compared to other groups of respondents). Respondents living outside downtown areas evaluated the images without green facades (A) less negatively and at the same time they rated the images featuring green facades ( $\mathrm{B}$ and $\mathrm{C}$ ) higher (similar to the Dutch respondents). The reasons for this are most likely connected with the fact that green facades are more common in the Netherlands than in Slovenia, where the residents of downtown areas are not used to them.

The evaluations of urban spaces provided by the general public and professional community show that in both countries the professional community rated images with green facades (B and $C$ ) half a point higher on average than the general public. A more detailed comparison between architecture and urban planning students (i.e., the professional community) and other students showed similar results: the former rated images with green facades higher. The general public evaluated type A images (without green facades) less negatively than the professional community, whereas it rated type $\mathrm{B}$ and $\mathrm{C}$ images lower than the professional community. The comparison of architecture students and urban planning (and similar) students alone shows that urban planning students rated spaces with green walls significantly higher than architecture students. The greatest difference (by approximately 1 point) can be seen with regard to type $\mathrm{A}$ images (without green facades) featuring real urban spaces: urban planning (and similar) students rated these spaces higher than architecture students, which many indicate that differences in the perception of urban spaces are already appearing within the professional community surveyed.

\subsection{Perception of various types of green walls}

In examining the evaluations of images by type of green walls (i.e., green facade or living wall), certain limitations need to be taken into account in relation to the methodological approach applied and the visual images presented. Most images showed urban ambiences, with green facades visible from afar and not up close. The differences between the two types (green facades and living walls) are visible, but all the technical details are not. The evaluations of the attractiveness of an individual type are thus based on a wider spatial impression. The results show that on average images showing green facades (GF) or ground-bound climbing plants were better rated than images of living walls $(\mathrm{LW})$. The mean value for GF was 2.65 and for LW 1.98. The maximum mean values are comparable for both types of green facades $(\max . \mathrm{GF}=8.23$, $\max . \mathrm{LW}=8.28)$, but nonetheless the mean for GF is higher than for LW because the GF ratings are less dispersed, whereas the $\mathrm{LW}$ ratings also range to the lowest negative values.

Similar results were obtained when comparing the respondents' preferences by country and sex. In the Dutch sample, the difference between the ratings of both green wall types is smaller than in the Slovenian one. This is expected because GF is the only type that has been historically present in Slovenia, whereas living walls have only appeared there recently. The comparison between both sexes in the two countries also 


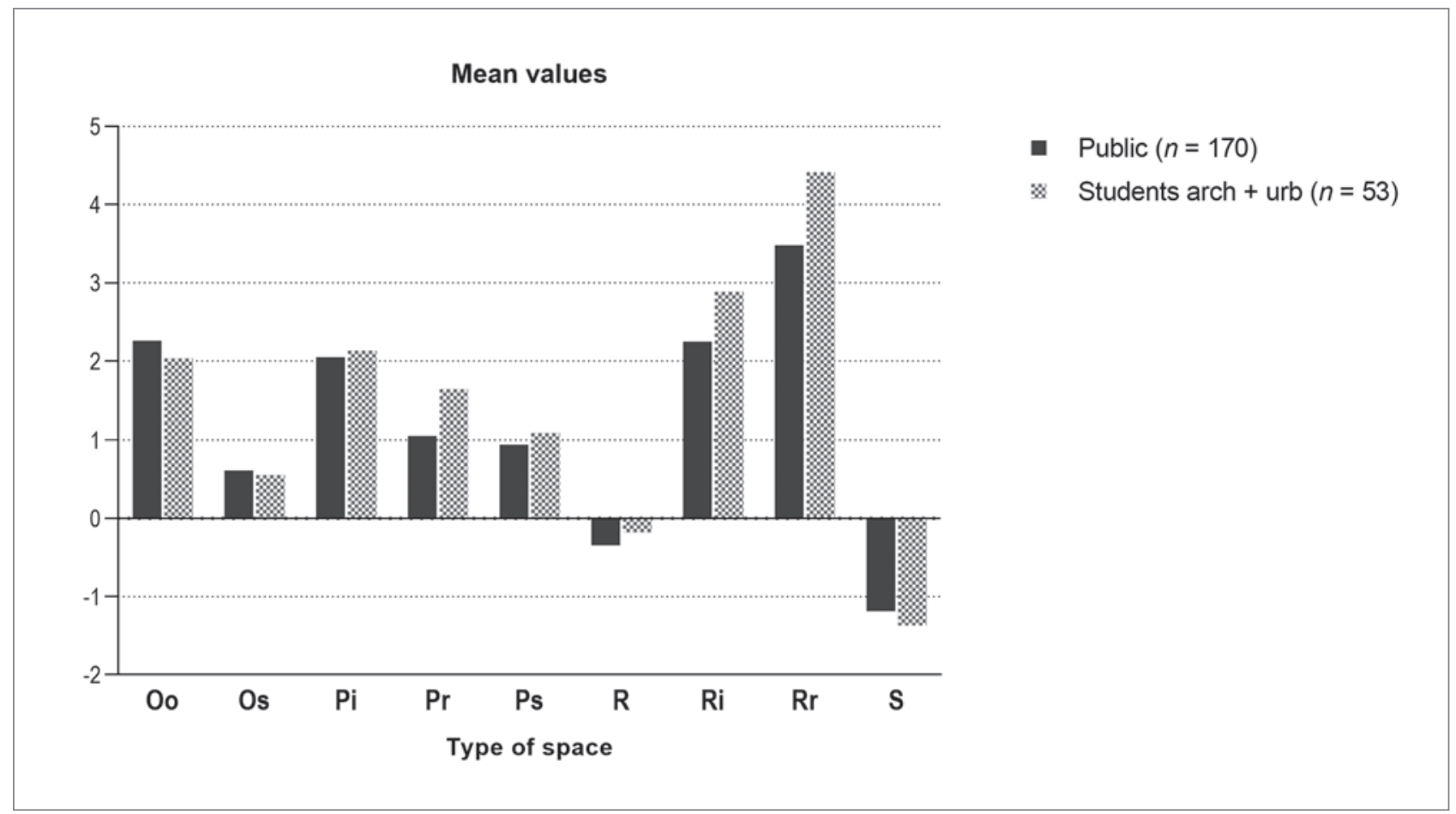

Figure 7: Mean values for individual types of urban space based on responses by the general public and the professional community ( $n=223$ ) (author: Jana Kozamernik).

shows the same results: images showing the GF type are better rated. The average rating of this type among men was 0.82 points higher than that of living walls, whereas the difference among women was slightly smaller: 0.56 points. The results of comparing age groups show that the perception of green wall types among the younger population does not differ significantly from that of the older population: respondents in all age groups rated green facades better than living walls, irrespective of the country, and the place or environment they live in. Even though the residents of Slovenian downtown areas provided the lowest ratings, they too find spaces with green facades more attractive. A similar result was obtained by comparing the two groups (i.e., the general public and the professional community).

\subsection{Types of urban spaces}

The study uses only a small sample of urban space types (i.e., twenty ambiences) and therefore the results can be interpreted as respondents' opinions about concrete images, but they are more difficult to generalize. The examples of spaces that people use daily were divided into categories according to the functions of spaces and buildings (open spaces and spaces connected with residential, shopping, and public buildings). 3D renders were analysed separately from images of real spaces (photos), even though 3D renders have a similar, realistic effect. Among the images of real situations, re- spondents found open public spaces where people often spend time (e.g., squares and playgrounds) and areas next to public buildings the most attractive. In turn, they considered shopping and business areas the least attractive. A 3D visualization of a modern apartment building, which received high ratings, can be highlighted among the more attractive examples.

A comparison between the two countries shows that even though the Slovenian respondents provided lower ratings overall, the average Slovenian and Dutch ratings of public open spaces (e.g., squares and playgrounds) were almost identical. Compared to the professional community, the general public rated all open spaces included in the survey (especially those with a multipurpose function or where people spend time, such as squares and playgrounds) higher. In turn, they rated residential areas and all spaces presented as 3D renders significantly lower than the professional community (Figure 7). The results also show that urban open spaces were best rated by the residents of urban areas and lower by residents of rural areas. Shopping and business centres were evaluated the worst.

\section{Discussion}

The perception of urban environments is greatly affected by natural elements. With their presence on the buildings, green facades as elements of vegetation and green infrastructure contribute to a greater attractiveness of the urban environment. 
The fact that spaces with green facades are evaluated as more attractive than those without them is also an expected result based on previous research exploring the importance of the presence of natural elements in the living environment and the positive effect of vegetation on the perception of space.

The perception of space (through the examined evaluation of green facades as elements of urban space) also depends on the respondents' sociodemographic characteristics. Differences were established in the ratings of various age groups in the two countries studied, especially young people and the elderly, which may indicate certain culturological differences between the countries. The major deviations of results for respondents living in downtown areas prompts the question of why Slovenian respondents evaluate urban ambiences significantly more critically than their Dutch counterparts. This group provided low ratings for all the categories of images presented (the lowest compared to other groups), which suggests that these people may also be more critical toward the living environment in general. In this regard, it would make sense to expand this study to obtain information on green facades and urban green elements in general from other countries, to focus on a comparison between urban and other residents, and to continue to incorporate the views of the professional community in research.

One of the key findings is the importance of not only the presence, but also the amount of vegetation in the urban context. Based on the results it can be concluded that the public opinion favours a larger share of vegetation in the urban environment. This said, it needs to be highlighted that the results are closely connected with the visual images used. They presented realistic scenarios of installing green facades, albeit with a different degree of vegetation cover, but always within the scope appropriate for the building to which they are attached, in an appropriate maintenance condition, and during their growth period. A larger respondent sample and additional images (even ones showing less attractive and poorly maintained spaces) could improve the understanding of the responses provided, which are not necessarily connected with the amount of greenery used, but also with the evaluation of these elements based on their condition. Nonetheless, it can be concluded from the results that in general people highly value urban ambiences with a higher amount of greenery, which is key from the perspective of urban design and guidelines for planning these urban spaces.

The respondents' preferences for various types of green walls were logically analysed in reference to the results of a 2011 study (White \& Gatersleben, 2011), according to which the vegetation system used and the type of vegetation selected have a great impact on the respondents' views. The findings of the survey presented in this article show that people find the traditional type of green facades more attractive or that they are more reserved toward modern vegetation systems (living walls). However, it needs to be highlighted that the survey did not examine individual types in detail; given the scale of the images used, differences between the systems or individual types were nonetheless visible. The findings of this survey suggest that people in urban environments would accept the GF type better or with fewer reservations.

To study the urban environments themselves, a greater diversity and a larger sample of images of individual ambiances would be required, which was not possible in this study due to the methodology used and is considered one of the its limitations. The study gave priority to various versions of images showing the same ambience and used a limited number of images because it also needed to ensure that the questionnaires were not too long. Despite the limited sample of urban space images, it can be established that open public spaces and areas next to public buildings play a significant role in the users' perceptions. These are places of social interaction, where people hang out, usually constituting a designed or planned open space. Respondents were more critical toward spaces directly connected to residential buildings or areas, and outdoor spaces at shopping centres, which were rated the worst, are probably perceived by users as environments of the poorest quality. Based on the study's results, attention should also be drawn to the fact that similar future studies should take into account that identifying well-known real-life motifs can affect the respondents' ratings and that $3 \mathrm{D}$ visualisations may be too idealized, which can again affect the ratings. In the future, it would make sense for studies to limit the images used to concrete spaces that respondents are not familiar with and to include a broader sample of the professional community (both students and active professionals).

In the future, it would make sense to expand the studies that focus on visual perception alone with comparative methodology or to conduct them in a way that would also involve other senses. It should be noted that this study's limitation is connected with the images prepared, but partly also with the amount of the data captured or their use in a detailed analysis. Limitations relating to the images have to do with the number of photos, the physical characteristics of the ambiances presented, and the decision on what should be shown in the images (i.e., the amount of greenery had to be appropriate and the green facades had to be well-maintained). The main cause of the limitations was the length of the questionnaire applied. Due to the large number of images used and the method of examining the green element studied, the survey included a small selection of individual space types. This limitation resulted in the low reliability of findings concerning the evaluations 
of individual urban space types. Despite adjustments made to shorten the questionnaire, many were only half completed and thus had to be eliminated from the analysis. The reliability of the study's results is hence also limited in terms of individual respondents' subgroups; for example, a smaller number of questionnaires completed by a specific group (e.g., the oldest population and respondents living in a rural environment). A minor limitation from the perspective of studying culturological differences is the international comparability of the study because it is limited to differences between Slovenia and the Netherlands alone, excluding other countries.

\section{Conclusion}

Understanding people's attitudes toward the urban environment and the presence of natural elements in it is key for defining the quality criteria and guidelines in planning these spaces. The study elucidates the effect of green facades on the perception of urban open spaces. The methodology used made it possible to include a wide circle of respondents from two European countries and the research material prepared can be combined with other methodologies in the future. The findings about the impact of green walls on the perception of urban ambiences suggest that green infrastructure plays a vital role in spatial users' perception in general. The findings show that it would also make sense to devote more attention to other studies of urban green infrastructure, and to compare the role of green facades to other elements of the green system. In making concrete decisions about installing green facades, attention should be paid to selecting the right sites, architectural acceptability, and environmental responsibility. It is key that urban planners are aware of the importance of the presence of green elements and treat them as factors enhancing spatial quality in both emerging as well as existing and less attractive urban environments.

\section{Jana Kozamernik}

Urban Planning Institute of the Republic of Slovenia, Ljubljana,

Slovenia

E-mail: jana.kozamernik@uirs.si

Martin Rakuša

Department of Neurology, University Medical Centre Maribor, Maribor, Slovenia

E-mail: ris101@gmail.com

\section{Matej Nikšič}

Urban Planning Institute of the Republic of Slovenia, Ljubljana,

Slovenia

E-mail: matej.niksic@uirs.si

\section{Acknowledgments}

This study was conducted as part of the project "H5-8287 Urban vertical green 2.0: Vertical greening for living cities - co-creative innovation for the breakthrough of an old concept" financed by the Slovenian Research Agency. The project was implemented under the Joint Programming Initiative Urban Europe within the joint call Sustainable Urbanization Global Iniative (SUGI) / Food-Water-Energy Nexus (ERA-NET Cofund SUGI).

The authors would like to thank the students and their mentors at the School of Governance, Law, and Urban Development of the Saxion University of Applied Sciences ("stadsLAB", year 2018/2019) for disseminating the online questionnaire in the Netherlands, Studio Krištof arhitekti d.o.o. for giving us permission to use two of their visualizations in the survey, and Rebeka Falle for providing assistance in statistical data analysis.

\section{References}

Bell, P. A. (2001): Environmental psychology. Belmont, Thomson-Wadsworth.

Bustami, R. A., Belusko, M., Ward, J., in Beecham, S. (2018): Vertical greenery systems: A systematic review of research trends. Building and Environment, 146, pp. 226-237. DOI: 10.1016/j.buildenv.2018.09.045

Carmona, M., Heath, T., Oc, T., in Tiesdell, S. (2003): Public places urban spaces: The dimensions of urban design. Amsterdam - Tokyo, Architectural Press.

Černigoj, N. (2018): Spajanje narave in arhitekture: ozelenitev stavb za mesta prihodnosti. Mladina, 25(6), pp. 54-56.

Fieandt, K. von (1966): The world of perception. Chicago, Dorsey Press.

Guan, X., Roös, P., in Jones, D. S. (2018): Biophilic city, vertical city, forest city? Towards an Architectree. V: IFLA 2018: Biophilic city, smart nation, and future resiliencee: Proceedings of the 55th International Federation of Landscape Architects World Congress 2018, pp. 814-826. Singapur, IFLA.

Haesevoets, F. (2015): A city hall in Belgium to have a patchwork of mini green walls. Available on: https://dzinetrip.com/a-city-hall-in-belgiumto-have-a-patchwork-of-mini-green-walls/ (accessed 2. 7. 2019).

Hayles, C., in Aranda-Mena, G. (2018): Well-being in vertical cities: Beyond the aesthetics of nature. V: Rajagopalan, P., in Andamonand, M. M. (ed.): 52nd International Conference of the Architectural Science Association, pp. 331-338. Melbourne, The Architectural Science Association and RMIT University.

Internet 1: https://c2cvenlo.nl/en/city-hall-venlo/ (accessed 10 July 2019).

Internet 2: http://www.studiokristof.com/projects/pr5/index.html (accessed 15 Apr. 2019).

Internet 3: http://www.studiokristof.com/projects/ts2/index.html (accessed 15 Apr. 2019).

Internet 4: https://venhoevencs.nl/projects/sportplaza-mercator/ (accessed 22 July 2019).

Jackson, J. B. (1994): A sense of place, a sense of time. New Haven, Yale University Press.

Jim, C. Y. (2015): Greenwall classification and critical design-management assessments. Ecological Engineering, 77, pp. 348-362. DOI: 10.1016/j.ecoleng.2015.01.021 
Köhler, M. (2008): Green facades - a view back and some visions. Urban Ecosystems, 11(4), str. 423-436. DOI: 10.1007/s11252-008-0063-x

Lu, Y., Sarkar, C. \& Xiao, Y. (2018) The effect of street-level greenery on walking behavior: Evidence from Hong Kong. Social Science and Medicine, 208(2), pp. 41-49. DOI: 10.1016/j.socscimed.2018.05.022

Mansor, M., Zakariya, K., Harun, N. Z. \& Abu Bakar, N. I. (2017) Appreciation of vertical vreenery in a vity as public. Planning Malaysia Journal, 15(1), pp. 117-128. DOI: 10.21837/pmjournal.v15.i6.227

Medl, A., Stangl, R. \& Florineth, F. (2017) Vertical greening systems - A review on recent technologies and research advancement. Building and Environment, 125, pp. 227-239. DOI: 10.1016/j.buildenv.2017.08.054

Montgomery, J. (1998) Making a city: Urbanity, vitality and urban design. Journal of Urban Design, 3(1), pp. 93-116. DOI: $10.1080 / 13574809808724418$

Nikšič, M. (2008) Povezovanje urbanih mikroambientov $v$ prepoznavno celoto $=$ Connecting urban microambients into recognizable whole: strukturiranost odprtega javnega prostora mesta $v$ miselni sliki uporabnikov = Structure of open urban public space in mental image of users. Doctoral dissertation. Ljubljana, Univerza v Ljubljani, Fakulteta za arhitekturo.

O'Hare, A. J., Atchley, R. A. \& Young, K. M. (2017) Valence and arousal influence the late positive potential during central and lateralized presentation of images. Laterality, 22(5), pp. 541-559.

DOI: $10.1080 / 1357650 X .2016 .1241257$

Passini, R. (1992) Wayfinding in architecture. New York, Van Nostrand Reinhold.

Perini, K. \& Rosasco, P. (2013) Cost-benefit analysis for green façades and living wall systems. Building and Environment, 70(12), pp. 110-121. DOI: 10.1016/j.buildenv.2013.08.012

Pfoser, N. (2016) Fassade und Pflanze, Potenziale einer neuen Fassadengestaltung. Doctoral dissertation. Darmstadt, Technische Universitat Darmstadt.

Punter, J. (1991) Participation in the design of urban space. Landscape Design journal, 200, pp. 24-27.

Rapoport, A. (1977) Human aspects of urban form. Towards a man-environment approach to urban form and design. Oxford, Pergamon.

Rasmussen, S. E. (2001) Experiencing architecture. Cambridge, MA, The MIT Press.

Relph, E. (1976) Place and placelessness. London, Pion Ltd and Sage Publications Ltd.

Strumse, E. (1994) Environmental attributes and the prediction of visual preferences for agrarian landscapes in Western Norway. Journal of Environmental Psychology, 14(4), pp. 293-303.

DOI: $10.1016 /$ S0272-4944(05)80220-8

Šuklje Erjavec, I., Balant, M., Kozamernik, J. \& Nikšič, M. (2020) Zeleni sistem $v$ mestih in naseljih: Usmerjanje razvoja zelenih površin, priročnik. Ljubljana, Ministrstvo za okolje in prostor, Direktorat za prostor, graditev in stanovanja.

Tsantopoulos, G., Varras, G., Chiotelli, E., Fotia, K. \& in Batou, M. (2018) Public perceptions and attitudes toward green infrastructure on buildings: The case of the metropolitan area of Athens, Greece. Urban Forestry and Urban Greening, 34(June), pp. 181-195.

DOI: 10.1016/j.ufug.2018.06.017

Van Renterghem, T. (2019) Towards explaining the positive effect of vegetation on the perception of environmental noise. Urban Forestry \& Urban Greening, 40, pp. 133-144. DOI: 10.1016/j.ufug.2018.03.007
Vogelnik, B. (2013) Predlog kako rekonstruirati roške stolpnice. $A R$. Arhitektura, raziskave, 13(1), pp. 102-107.

White, E. V. \& Gatersleben, B. (2011) Greenery on residential buildings: Does it affect preferences and perceptions of beauty? Journal of Environmental Psychology, 31(1), pp. 89-98. DOI: 10.1016/j.jenvp.2010.11.002

Wong, N. H., Kwang Tan, A. Y., Chen, Y., Sekar, K., Tan, P. Y., Chan, D., et al. (2010a) Thermal evaluation of vertical greenery systems for building walls. Building and Environment, 45(3), pp. 663-672. DOI: 10.1016/j.buildenv.2009.08.005

Wong, N. H., Tan, A. Y. K., Tan, P. Y., Sia, A. \& Wong, N. C. (2010b) Perception studies of vertical greenery systems in Singapore. Journal of Urban Planning and Development, 136(4), pp. 330-338.

DOI: 10.1061/(ASCE)UP.1943-5444.0000034 